\title{
Wire Production Development \\ of Special Aluminum Alloys Based \\ on Electromagnetic Mold Casting Method \\ and Continuous Extrusion Process Known as Conform
}

\author{
Anton A. Avdulov, Nikolay V. Sergeev, \\ Ivan S. Gudkov, Viktor N. Timofeev, \\ Yuri V. Gorokhov and Yulia S. Avdulova* \\ Siberian Federal University \\ 79 Svobodny, Krasnoyarsk, 660041, Russia
}

Received 16.11.2016, received in revised form 14.12.2016, accepted 02.01.2017

It sets out the perspectives of special aluminum alloys use for the production of aircraft onboard wires. The description of the melt-casting complex based on electromagnetic mold method for casting of continuously cast ingots of small cross section area. Presented the advantages of electromagnetic casting method for structure and mechanical properties of ingots and wire of $01417 m$ alloy. Wire technological production scheme is shown, which includes casting method of continuous blank in electromagnetic mold and next step of plastic deformation process known as conform. Discussed the advantages of this production scheme and perspectives of its implementation in industry.

Keywords: aluminum alloys, aircraft wire, electromagnetic mold, continuous pressing, conformal.

Citation: Avdulov A.A., Sergeev N.V., Gudkov I.S., Timofeev V.N., Gorokhov Yu.V. Avdulova Yu.S. Wire production development of special aluminum alloys based on electromagnetic mold casting method and continuous extrusion process known as conform, J. Sib. Fed. Univ. Eng. technol., 2017, 10(1), 85-94. DOI: 10.17516/1999-494X-2017-10-1-85-94.

(C) Siberian Federal University. All rights reserved

* Corresponding author E-mail address: avdulov@mail.ru,mgd2@mail.ru 


\title{
Разработка технологии производства проволоки
}

\author{
из специальных алюминиевых сплавов
}

на основе способа литья

В электромагнитный кристаллизатор

и непрерывного прессования способом конформ

\author{
А.А. Авдулов, Н.В. Сергеев, И.С. Гудков, \\ В.Н. Тимофеев, Ю.В. Горохов, Ю.С. Авдулова \\ Сибирский федеральный университет \\ Россия, 660041, Красноярск, пр. Свободный, 79
}

Изложены перспективы использования специальных алюминиевых сплавов для производства бортовых проводов летательных аппаратов. Приведено описание плавильно-литейного комплекса с электромагнитным кристаллизатором для производства непрерывнолитых слитков малого сечения. Представлены преимущества электромагнитного литья, структуры и механические свойства слитков и проволоки из сплава 01417м. Предложена технологическая схема производства проволоки, включающая в себя литье непрерывной заготовки в электромагнитный кристаллизатор и ее последуюшую пластическую деформацию способом конформ. Приведены преимущества данной схемы и перспективы ее внедрения в промышленности.

Ключевые слова: алюминиевые сплавы, бортовые провода, электромагнитный кристаллизатор, непрерывное прессование, конформ.

\section{Введение}

Совершенствование авиационной и ракетно-космической техники заставляет решать задачу снижения массы летательных аппаратов. Бортовая кабельная сеть (БКС) является «нервной системой» летательных аппаратов и занимает существенную долю их массы (20-25 \%). Мировая тенденция снижения массы проводников - использование в качестве основного материала алюминиевых сплавов взамен меди. Однако достигнутые в настоящий момент свойства проволоки из специальных алюминиевых сплавов не обеспечивают одновременно высокой электропроводности и жаропрочности, что критически важно для БКС авиакосмической техники. В связи с этим рабочие температуры алюминиевых проводов БКС не превышают $100-180{ }^{\circ} \mathrm{C}$ при требуемых $250{ }^{\circ} \mathrm{C}$. При этом существующие промышленные технологии не позволяют с высоким выходом годной продукции изготавливать проволоку из специальных сплавов диаметром менее 0,5 мм, что также ограничивает внедрение алюминиевых проводов в авиакосмическую технику. Дефицит такой кабельной продукции восполняется отечественными потребителями за счет закупок исключительно импортных проводов и кабелей, что никогда не приветствовалось государственным заказчиком.

Зарубежные производители авиатехники в последние годы активно занимаются разработкой и внедрением алюминиевых проводов.

Так, например, «двухэтажный» AIRBUS A380 является первым самолетом компании, где применены алюминиевые кабели и провода с сечением меньше 5 кв. мм, что позволило 
дополнительно снизить вес БКС на 500 кг. Для сравнения: это больше половины экономии веса, полученного за счет изготовления из углеволокна центроплана (Central Torsion Box), на разработку которого были потрачены миллионы евро. В дальнейшем AIRBUS планирует использовать данное решение на A400M и A350XWB. Всего в A380 в 300 из 500 км проводов и кабелей используют алюминий вместо обычной меди в качестве электрического проводника, что позволило снизить вес БКС на 20 \%. При этом в качестве проводниковой жилы приходится применять аналог отечественного сплава АМГ1, имеющего допустимую рабочую температуру только до $180{ }^{\circ} \mathrm{C}$ и существенно большее сопротивление по сравнению с чистым алюминием.

С 2005 г. в ходе реализации программы по импортозамещению $\mathrm{AO}$ «Особое конструкторское бюро кабельной промышленности» (ОКБ КП - головное предприятие в РФ, занимающееся разработкой и производством бортовых проводов) проводит ОКР по созданию серии облегченных кабельных изделий для авиационной техники с использованием новых отечественных изоляционных и проводниковых материалов. В настоящее время в АО «ОКБ КП» разработаны бортовые провода с токопроводящими жилами из алюминиевого сплава и комбинированной изоляции марок [1]:

- БК-36-448 и БКЭ-36-448 по ТУ 16.К76-236-2009 сечением от 4 до 95 мм² с никелевым покрытием, рабочей температурой $200{ }^{\circ} \mathrm{C}$;

- БФС-А и БФСЭ-А теплостойкие по ТУ 16-705.405-85 сечением от 4 до 95 мм² без покрытия, рабочей температурой $250{ }^{\circ} \mathrm{C}$.

Более высокая максимальная рабочая температура отечественных проводов по сравнению с зарубежными достигается за счет использования жилы из сплава алюминия с редкоземельными металлами 01417 [2, 3]. При освоении производства проволоки из сплава 01417 существующими технологиями было обнаружено, что из-за крупнозернистой и неоднородной микроструктуры производство проволоки малых диаметров экономически нецелесообразно (высокая обрывность при волочении).

\section{Получение непрерывно-литой заготовки способом литья в электромагнитный кристаллизатор}

Для решения проблемы получения качественной проволоки из сплава 01417 специалистами ООО «НПЦ Магнитной гидродинамики» совместно с сотрудниками Сибирского федерального унивеститета и ООО «АвиаСпецСплав» была разработана уникальная технология литья в электромагнитный кристаллизатор (ЭМК), которая позволяет получить проволоку из жаропрочных алюминиевых сплавов со структурой, сопоставимой со структурой гранул (порошковая металлургия). В отличие от работ 3.Н. Гецелева [4] в электромагнитный кристаллизатор производится отливка слитков малого сечения (диаметр менее 20 мм). Сплав 01417 был доработан для возможности литья в электромагнитный и получил обозначение 01417м. При этом технология обеспечивает существенно более высокую производительность, низкую себестоимость, требуемые технические характеристики и высокое качество выпускаемой продукции.

В ООО «НПЦ Магнитной гидродинамики» создан опытно-промышленный литейный комплекс с электромагнитным кристаллизатором производительностью до 20 т в год непрерывнолитой заготовки диаметрам 8 мм (рис. 1). По тематике работы защищены три докторских 
и пять кандидатских диссертаций. На опытно-промышленной установке получены слитки из сплава 01417м, обладающие высокими механическими и электрическими свойствами, сохраняющимися до температуры $250{ }^{\circ} \mathrm{C}$. В партнёрстве с ОКБ КП и НПЦ «АвиаСпецСплав» из полученных слитков изготовлены провода для БКС самолетов-амфибий Бе-200, что позволило снизить вес машины на 1 т. Разработана технология волочения литой заготовки до диаметра 0,5 мм.

Суть технологии заключается в кристаллизации алюминиевого расплава в высокочастотном электромагнитном поле с непосредственной подачей охлаждающей воды на слиток. Вследствие этого происходит бесконтактное формирование слитка диаметром 8-12 мм со скоростью охлаждения свыше $1000 \mathrm{~K} / \mathrm{c}$ и интенсивным магнитогидродинамическим воздействием на границе раздела фаз, что обеспечивает получение дисперсной структуры $[5,6]$.

На рис. 2 представлена принципиальная схема работы комплекса. В плавильной печи (1) осуществляется приготовление алюминиевого сплава, однородность по химическому составу и температуре обеспечивается путем использования электромагнитного перемешивателя (2). Расплав из плавильной печи (1) поступает в дозирующий лоток (3), где поддерживается заданная температура и уровень расплава. Через подающий носик лотка расплав продвигается в индуктор электромагнитного кристаллизатора (4), в котором геометрия слитка бесконтактно формируется высокочастотным электромагнитным полем. Охлаждающая жидкость из охладителя (5) непосредственно подается на заготовку, что обеспечивает высокую скорость охлаждения и позволяет получить непрерывно-литую заготовку (6). Заготовка далее с помощью отводного механизма выводится из кристаллизатора и наматывается в бухту.

Преимущества непрерывно-литых заготовок, полученных по технологии литья в электромагнитный кристаллизатор:

- слиток, полученный по технологии литья в электромагнитный кристаллизатор, имеет дендритный параметр в 100 раз меньше, чем в кристаллизаторе скольжения, и сопоставим со структурой гранул (рис. 3);

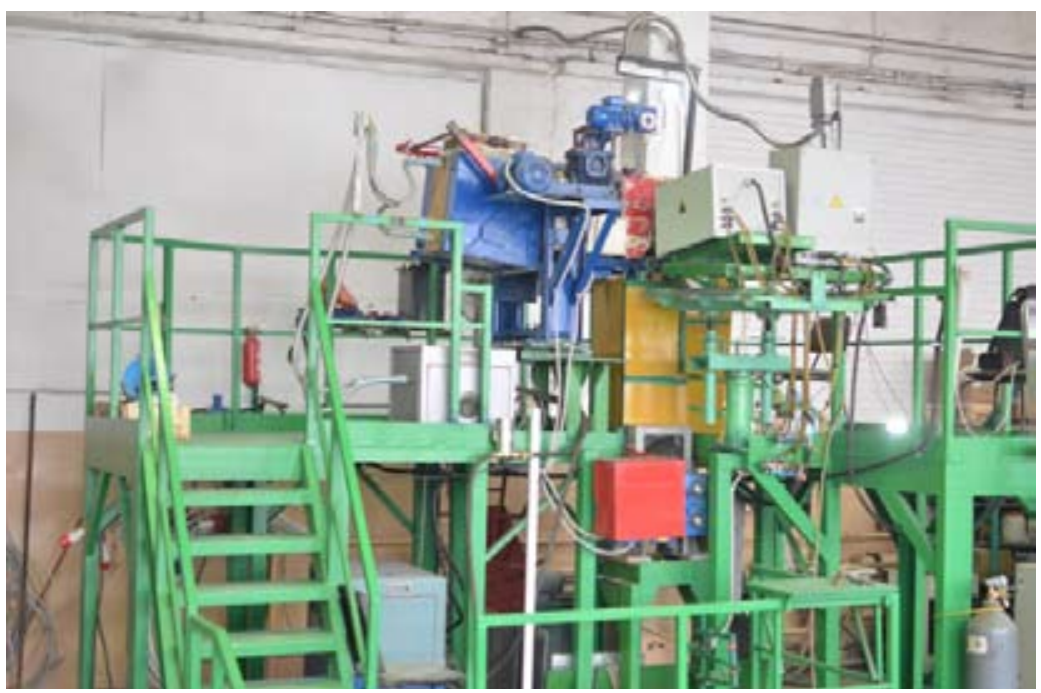

Рис. 1. Плавильно-литейный комплекс с электромагнитным кристаллизатором 
- в слитках практически отсутствует дендритная ликвация;

- благодаря высокой скорости кристаллизации происходит расширение концентрационных областей твердых растворов, сдвиг эвтектических и перитектических точек, что

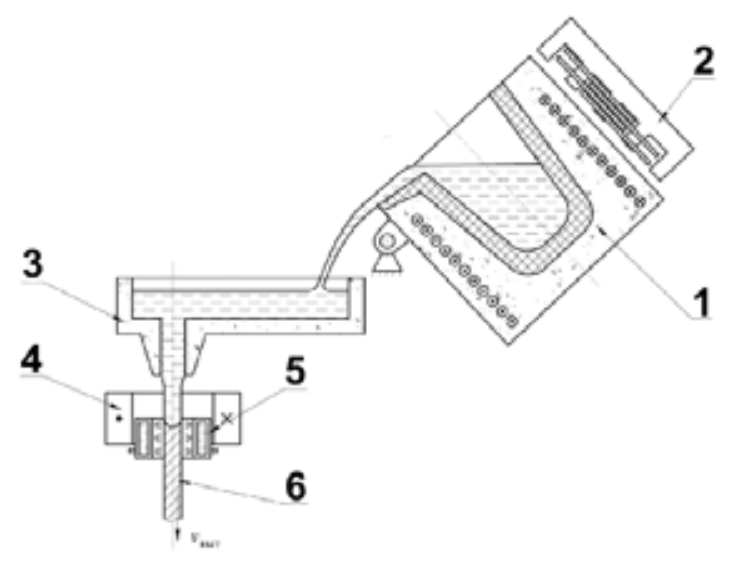

Рис. 2. Принципиальная схема комплекса с ЭМК

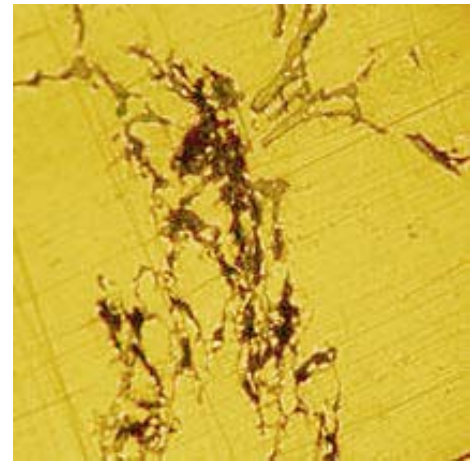

a

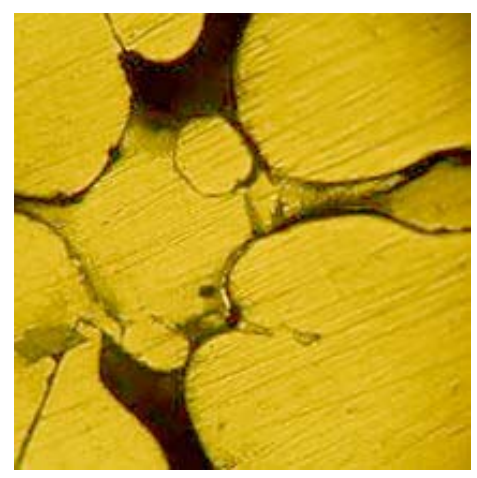

B

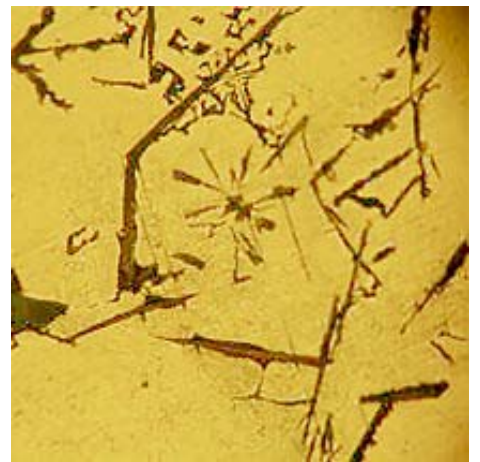

6

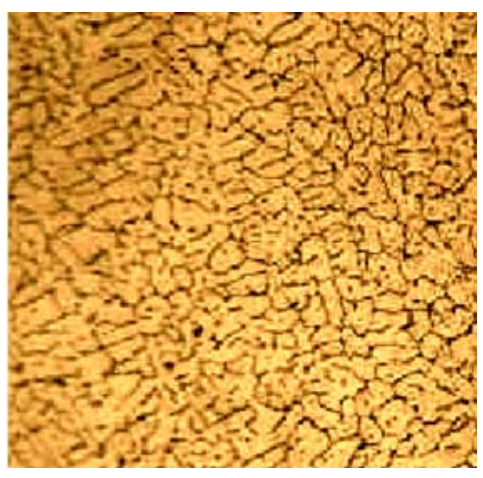

$\Gamma$

Рис. 3. Состояние сложнолегированного сплава: а - перед литьем, окисные плены; б - перед литьем, грубые первичные интерметаллиды; в - междендридная пористость; г - после литья в ЭМК, квазиэвтектическая структура без первичных интерметаллидов и оксидов 
позволяет обеспечить разработку новых сплавов и получение более высоких прочностных свойств в существующих сплавах;

- электромагнитное литье в отличие от гранульной технологии дает возможность получать изделия, уже готовые к дальнейшей переработке (нет необходимости производить обработку гранул, их спекание и т.д.);

- дальнейшая пластическая деформация заготовок приводит к образованию нанодисперсной эвтектики, что позволяет изготовить проволоку из специальных алюминиевых сплавов диаметром до 0,10 мм;

- уникальным свойством электромагнитного литья является отсутствие в изделиях неметаллических включений, что обеспечивает получение продукции высокого качества (рис. 3).

Микроструктура литых заготовок из сплава 01417м однородна, дисперсна по всему сечению, в ней отсутствуют первичные интерметаллиды (рис 4). Микроструктура представляет собой $\alpha$-твердый раствор, по границам дендритных ячеек которого располагается дисперсная эвтектика $(\alpha+\mathrm{AlnMe})$. Наименьший размер дендритной ячейки составил 4,1 мкм. Такая микроструктура свойственна сплавам Al-PЗМ, полученным с высокими скоростями охлаждения расплава (до $10^{3}{ }^{\circ} \mathrm{C} / \mathrm{c}$ ). Уровень прочностных свойств заготовок аналогичен свойствам горячепрессованных прутков из гранул сплава $01417 \mathrm{M}$, причем отпрессованных с высоким коэффициентом вытяжки $(\mu=55)$. Физико-механические свойства литой заготовки и проволоки из сплава 01417м приведены в табл. 1.

\section{Совмещение литья в ЭМК и непрерывного прессования в общей технологической цепи производства проволоки}

При массовом выпуске продукции процесс непрерывного литья на плавильно-литейном комплексе с электромагнитным кристаллизатором может длиться от 6 до 9 ч, а в перспективе - до нескольких суток. Это обеспечивает производство цельных бухт непрерывнолитых заготовок. Цельная бухта большой массы (свыше 80 кг) более предпочтительна, так как при волочении сокращается количество технологических операций (зачистка, стыковка, сварка и т.п.). Поскольку формообразование слитка происходит в электромагнитном поле, то небольшие изменения технологических параметров могут привести к появлению дефектов литья (рис. $56,6,2$ ). При дальнейшей переработке слитка в проволоку путем во-

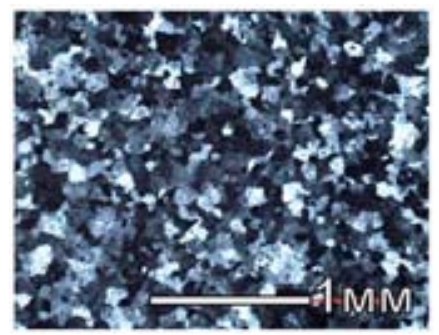

a

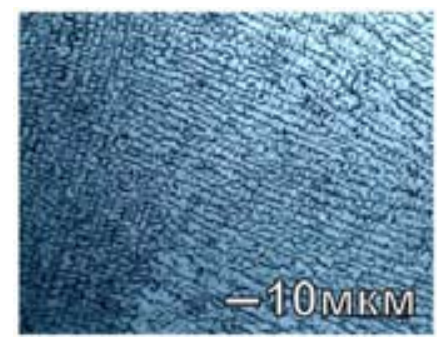

б

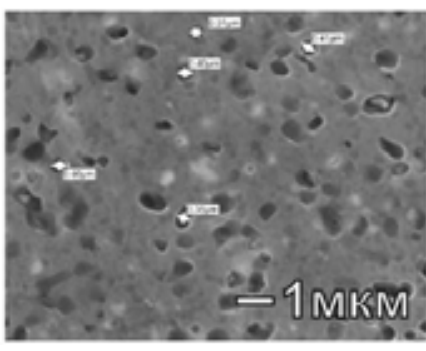

B

Рис. 4. Структуры изделий из сплава $01417 \mathrm{M}$ : а - макроструктура литой заготовки диаметром 8 мм; б - микроструктура литой заготовки диаметром 8 мм; в - микроструктура проволоки диаметром 0,5 мм 
Таблица 1. Механические свойства прутков литой заготовки и проволоки из сплава 01417м

\begin{tabular}{|l|c|c|c|}
\hline \multicolumn{1}{|c|}{ Изделие из сплава 01417м } & $\begin{array}{c}\text { Предел прочности, } \\
\text { МПа }\end{array}$ & $\begin{array}{c}\text { Относительно } \\
\text { удлинение, \% }\end{array}$ & $\begin{array}{c}\text { Допустимая рабочая } \\
\text { температура, } \\
\text { град. Цельсия }\end{array}$ \\
\hline $\begin{array}{l}\text { Непрерывно-литая заготовка } \\
\text { диаметром 8 мм }\end{array}$ & $185-210$ & $15-24$ & - \\
\hline Проволока диаметром 0,5 мм & 190 & 15 & до 250 \\
\hline
\end{tabular}

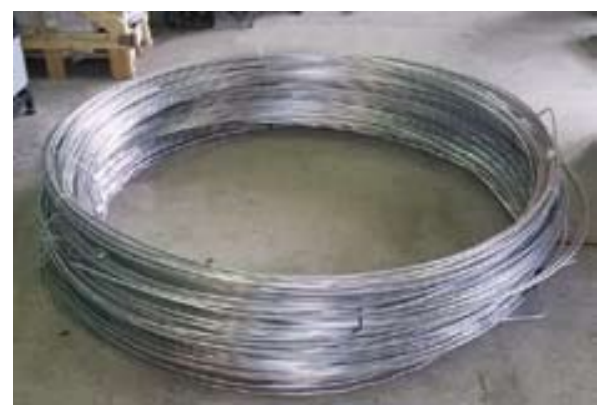

a

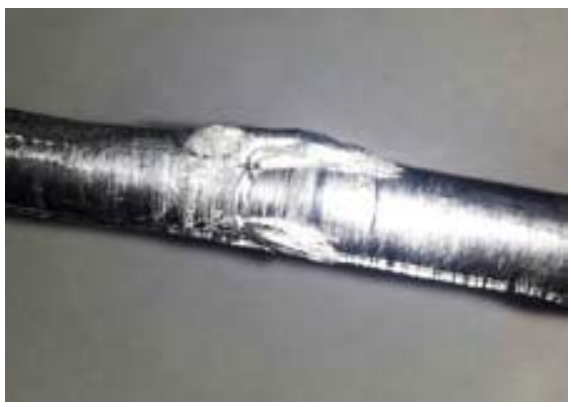

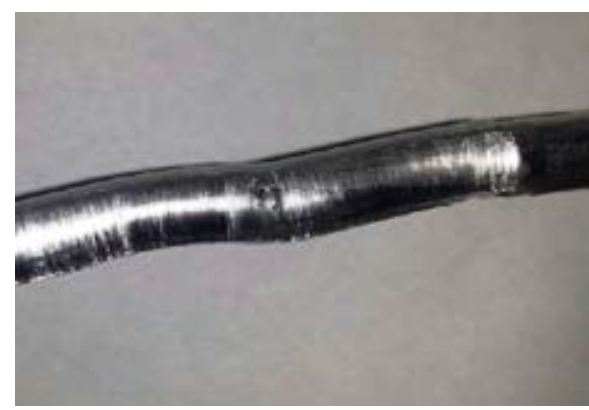

6

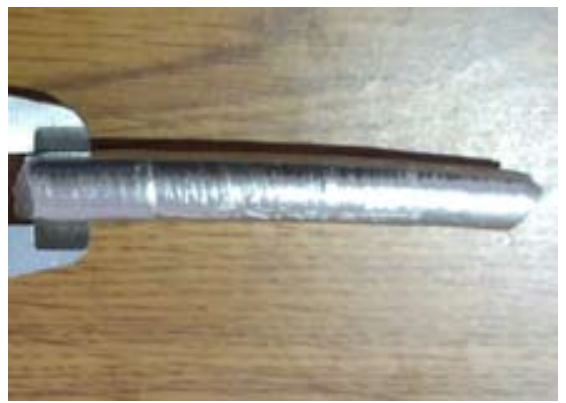

Рис. 5. Непрерывно-литая заготовка: а - в бухте; б - искривление слитка; в - наплыв на слитке; г - нестабильный диаметр слитка

лочения данные дефекты могут привести к обрывности проволоки, а в ряде случаев - к браку всей бухты.

В настоящий момент стоит задача повышения качества выпускаемой продукции - стабилизации диаметра слитка, что позволит повысить технологичность переработки изделий в проволоку и начать массовое внедрение алюминиевых проводов в авиакосмической отрасли. Для этого предлагается перед отправкой литых слитков на волочильный завод производить их калибровку с последующей непрерывной экструзией способом конформ [7, 8], что даст возможность поставлять потребителю продукт более глубокой переработки - калиброванную проволоку диаметрам до 5 мм. При этом данный способ позволит перевести мелкодисперсную эвтектику (1-3 мкм) в литом слитке в нанодисперсное состояние (менее 100 нм), что, по заверению специалистов-металловедов, даст возможность получить при дальнейшем волочении проволоку диаметром до 0,1 мм. 
Предлагаемая технологическая схема представлена на рис. 6. На первом этапе производится приготовление, очистка и литье сплава в электромагнитный кристаллизатор. В результате литья производится слиток диаметром 10-12 мм в бухте. Далее слиток подвергается калибровке в диаметр 10 мм. На последнем этапе переработки слиток поступает для непрерывного прессования способом конформ в проволоку диаметром 5 мм.

Для создания предложенной технологической схемы был разработан проект опытнопромышленной установки для калибровки слитка и непрерывной экструзии проволоки. Установка выполнена по модульному принципу и состоит из общей силовой рамы с моторредуктором и сменных модулей: модуля калибровочной клети (модуль Прокатка, рис. 7a) и модуля непрерывной экструзии (модуль Конформ, рис. 7б).

В состав установки входит разматывающее устройство для подачи исходного и калиброванного слитков в рабочие модули. Наматывающее устройство имеет собственный моторредуктор и механический укладчик проволоки, что обеспечивает плотную укладку проволоки в бухты с внутренним диаметром 650 мм. Полученные бухты после связки и маркировки являются товарной продукцией, готовой к отправке на волочильный завод.

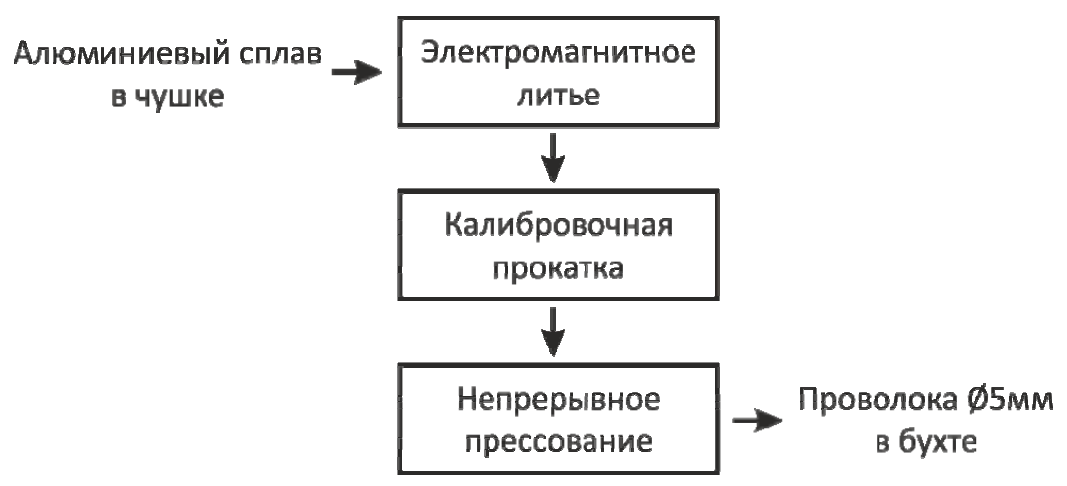

Рис. 6. Перспективная технологическая схема производства проволоки

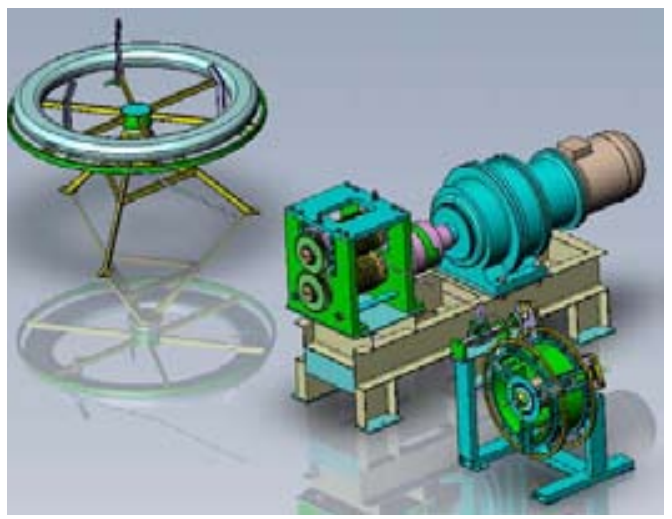

a

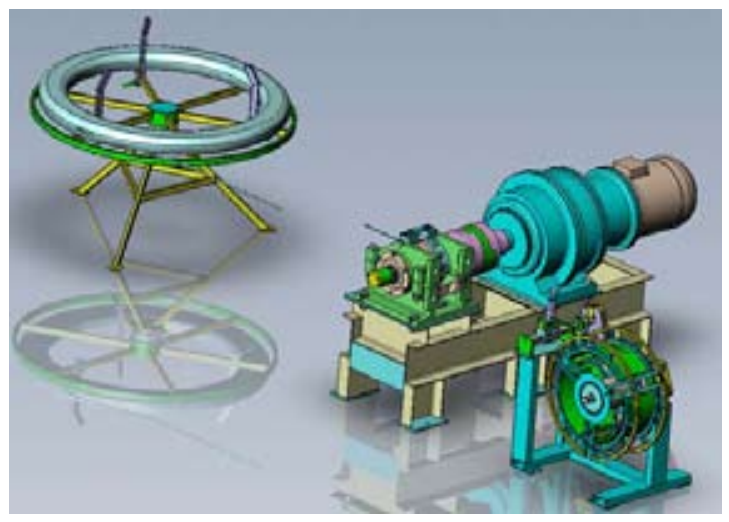

6

Рис. 7. Опытно-промышленная установка для калибровки слитка и непрерывной экструзии проволоки: а - с модулем конформ; б - с модулем прокатки 


\section{Заключение}

Технологическая линия, включающая в свой состав комплекс для литья в электромагнитный кристаллизатор непрерывно-литых слитков малого сечения и установку для непрерывного прессования способом конформ, должна обеспечить производство высококачественной проволоки с дисперсной структурой и стабильными физико-механическими свойствами. Это даст возможность начать широкое внедрение в промышленности стандартных и специальных алюминиевых сплавов с мелкодисперсной структурой.

Работы по разработке технологии переработки литой заготовки в проволоку путем прокатки и непрерывного прессования выполнены в рамках проекта «Разработка технологии производства проволоки из специальных алюминиевых сплавов для нужд авиакосмической промышленности». Проект поддержан Правительством Красноярского края и КГАУ «Красноярский краевой фонд поддержки научной и научно-технической деятельности» по конкурсу научно-технических проектов, направленных на кооперацию учреждений и организаций научно-образовательного комплекса Красноярского края по заказу промышленных предприятий в 2016 г.

Исследование выполнено при финансовой поддержке Российского фонда фундаментальных исследований, Правительства Красноярского края, Красноярского краевого фонда поддержки научной и научно-технической деятельности в рамках научных проектов № 16-48-242018 и № 16-43-242013 p_oфu_м.

\section{Список литературы}

[1] ОКБ КП [корпоративный сайт]. URL: http://www.okbkp.ru/ (дата обращения: 01.09.2016).

[2] Добаткин В.И., Елагин В.И. Гранулируемые алюминиевые сплавы. М.: Металлургия, 1983, 176 c. [Dobatkin V.I., Elagin V.I. Granulated aluminum alloys. Moscow, Metallurgy, 1983. 176 p. (in Russian)]

[3] Добаткин В.И., Елагин В.И. Быстрозакристаллизованные алюминиевые сплавы. М.: ВИЛС, 1995, 341 с. [Dobatkin V.I., Elagin V.I Quickly crystallized aluminum alloys. Moscow, VILS, 1995. 341 p. (in Russian)]

[4] Гецелев 3.Н. и др. Непрерывное литье в электромагнитный кристаллизатор. М.: Металлургия, 1983. 152 c. [Getselev S.N. and etc. Continuous casting in an electromagnetic mold. Moscow, Metallurgy, 1983. 152 p. (in Russian)]

[5] Первухин М.В. Электротехнология и оборудование для получения непрерывнолитых слитков в электромагнитном кристаллизаторе. Теория и практика: автореф. дис. ... д-ра техн. наук: 05.09.10. Красноярск, 2012. 36 c. [Pervukhin M.V. Electrotechnology and equipment for continuous casting ingot in an electromagnetic mold. Theory and Practice: Abstract. Dis. ... Doctor of Sciences:.. 05.09.10. Krasnoyarsk, 2012. 36 p. (in Russian)]

[6] Бааке Э. и др. МГД-технологии в металлургии. Интенсивный курс Специализаичия IV. Спб.: Изд-во СПбГЭТУ «ЛЭТИ», 2013. 250c. [А. Baake and etc. MHD technologies in metallurgy. Intensive Specialization I; SPb.: Publishing house of the ETU "LETI", 2013. 250 p. (in Russian)] 
[7] Сидельников С.Б., Горохов Ю.В., Беляев С.В. Инновационные совмещенные технологии при обработке металлов. Журнал Сибирского федерального университета. Техника и технологии, 2015, 8(2), 185-191 [Sidelnikov S.B., Gorohov U.V., Belyaev S.V., Innovative combined technologies for processing of metals. Journal of Siberian Federal University. Engineering and technology, 2015, 8(2), 185-191]

[8] Горохов Ю.В., Шеркунов В.Г., Довженко Н.Н., Беляев С.В., Довженко И.Н. Основы проектирования прочессов непрерывного прессования металлов. Красноярск: СФУ, 2013. [Gorohov U.V., Sherkunov V.G., Dovzhenko N.N., Belyaev S.V., Dovzhenko I.N. The basics of process design continuous extrusion of metals, Krasnoyarsk, SFU, 2013. (in Russian)] 